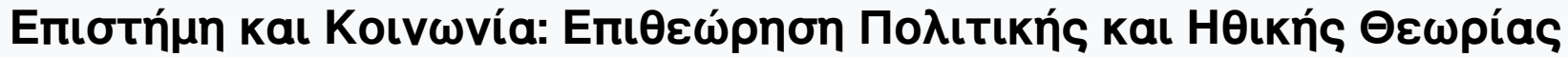

Tó 17 (2007)

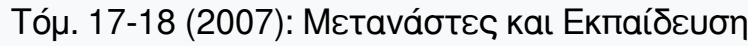

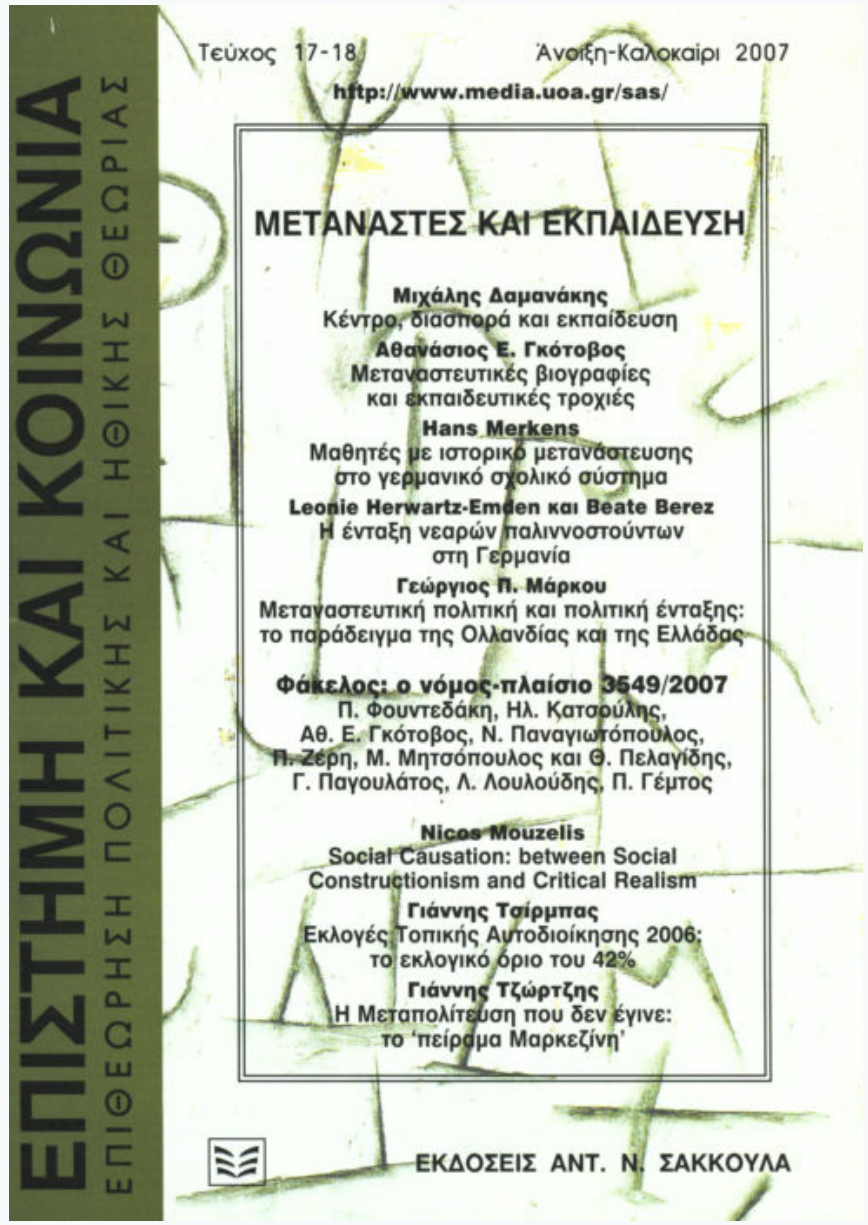

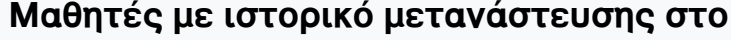

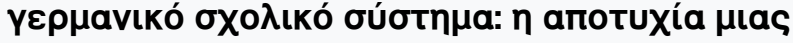

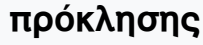

Hans Merkens

doi: $10.12681 /$ sas.491

Copyright (C) 2015, Hans Merkens

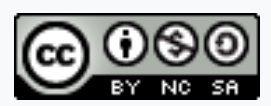

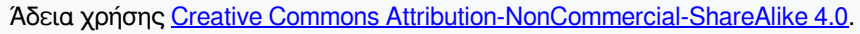

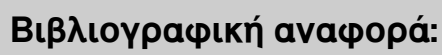

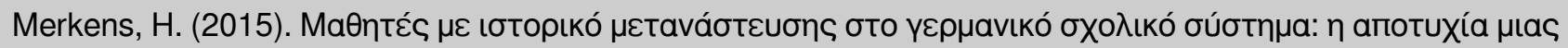

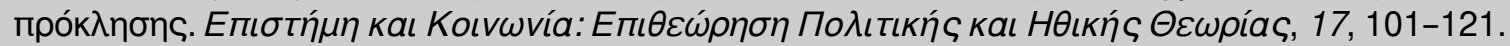

https://doi.org/10.12681/sas.491 


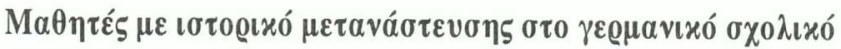

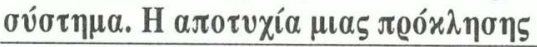

\section{Hans Merkens}

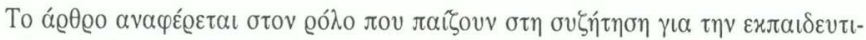

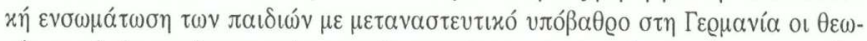

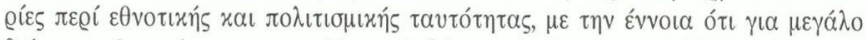

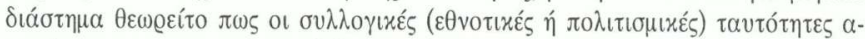

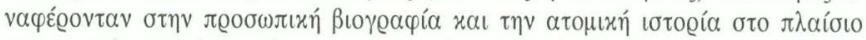

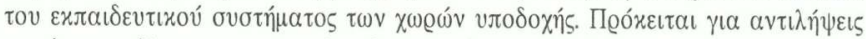

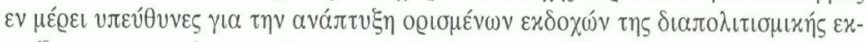

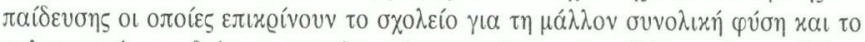

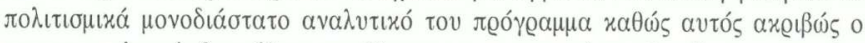

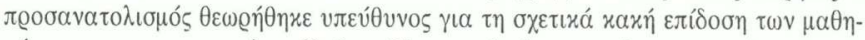

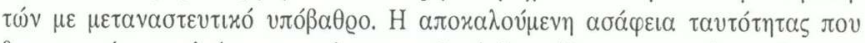

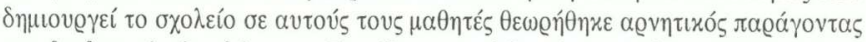

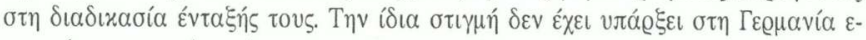

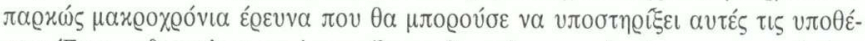

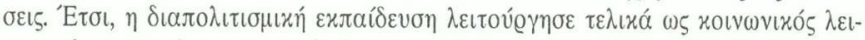

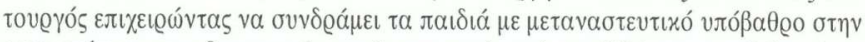

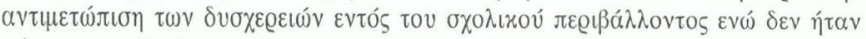

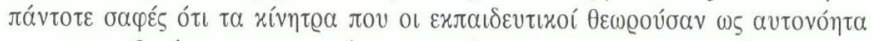

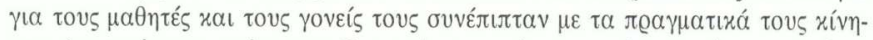

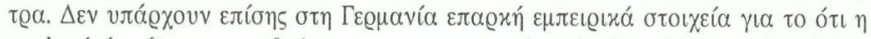

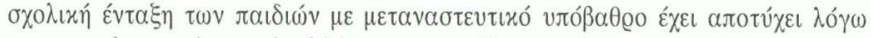

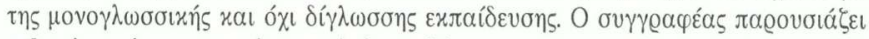

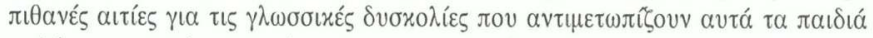

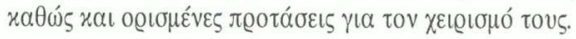

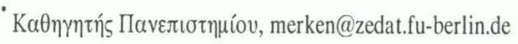




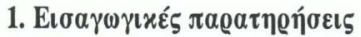

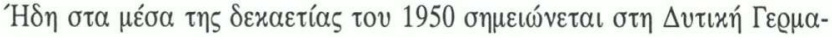

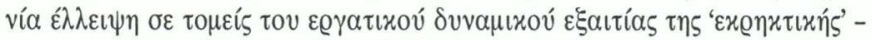

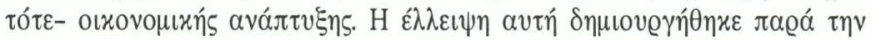

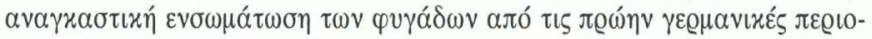

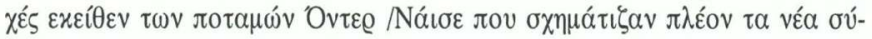

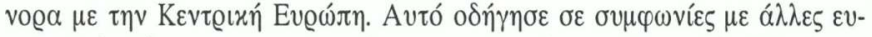

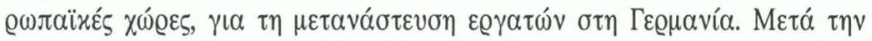

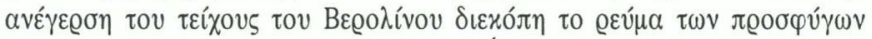

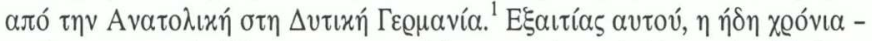

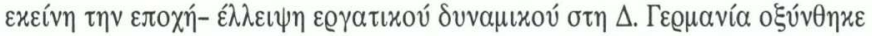

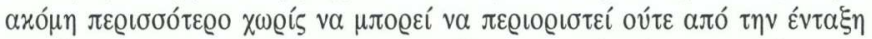

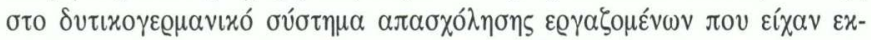

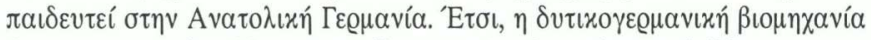

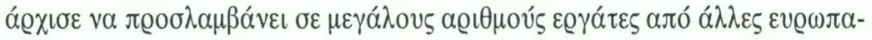

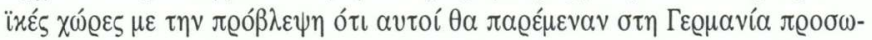

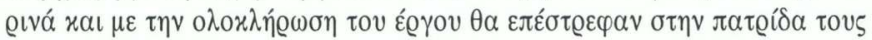
( $\beta \lambda$. Münz, Seifert xal Ulrich 1997: 38):

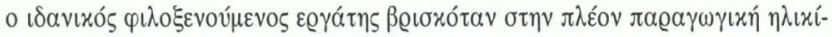

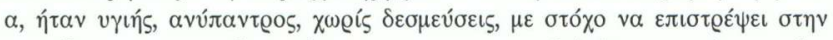

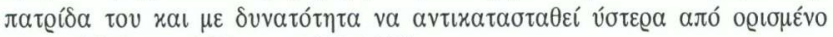

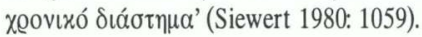

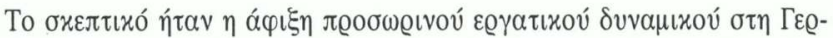

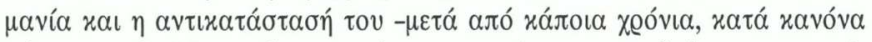

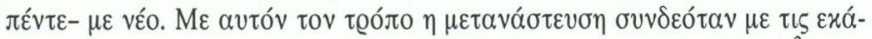

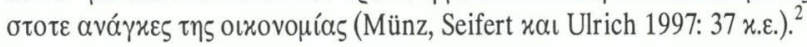

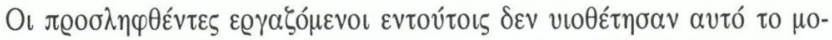

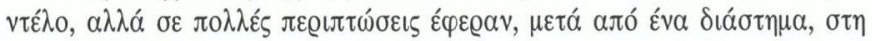

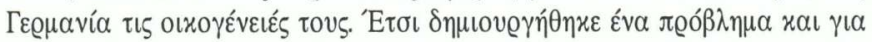

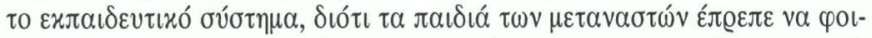

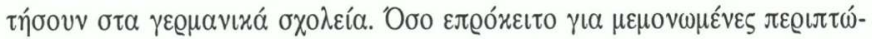

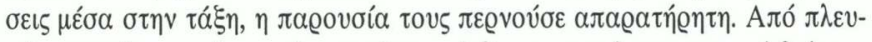

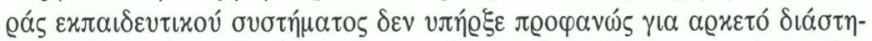

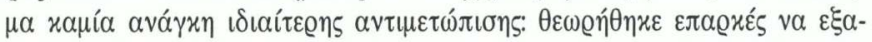

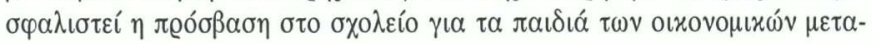




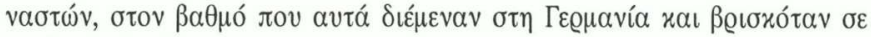

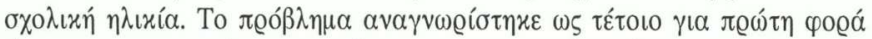

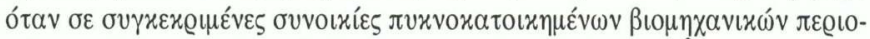

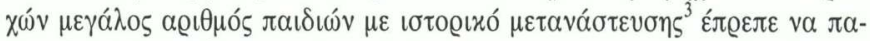

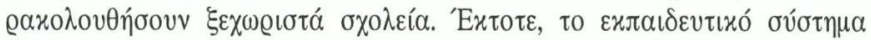

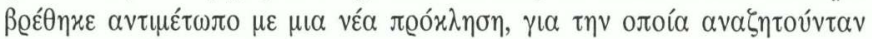
$\alpha \pi \alpha v \tau \dot{\sigma} \sigma \varepsilon ı \varsigma$ ( $\beta \lambda$. Herwartz-Emden 2003).

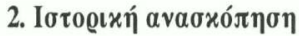

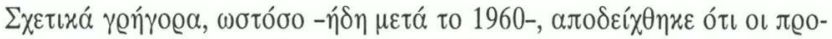

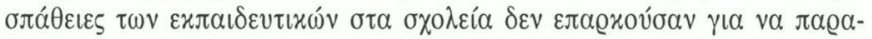

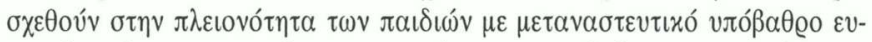

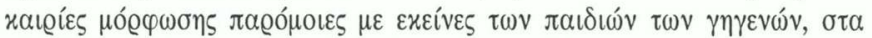

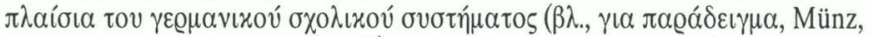

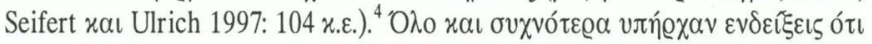

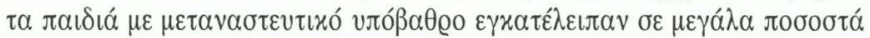

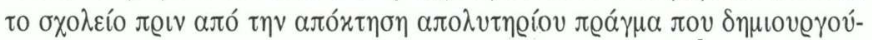
$\sigma \varepsilon \pi \varrho \circ \beta \lambda \eta \dot{\mu} \alpha \tau \alpha$ ( $\beta \lambda$. Merkens 1991, Herwartz-Emden 2003) $)^{5} \varepsilon \pi \alpha \varrho x o v ́ \varsigma \varepsilon v-$

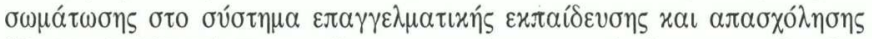

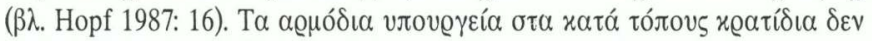

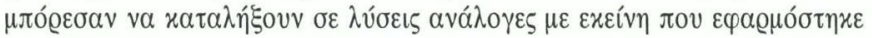

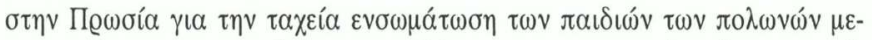

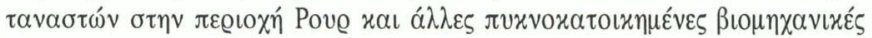

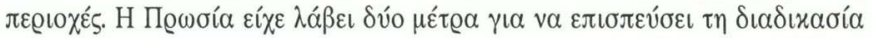

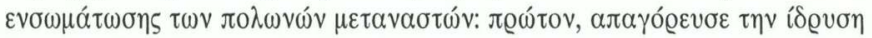

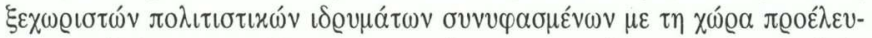

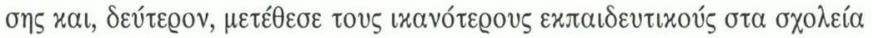

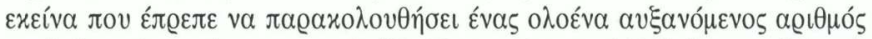

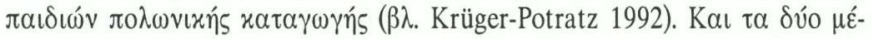

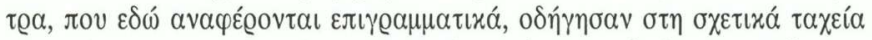

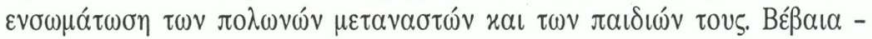

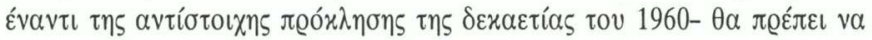

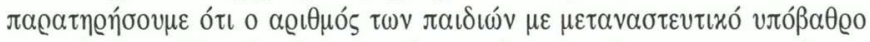

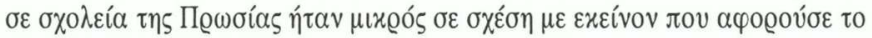

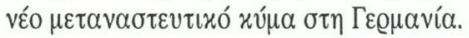




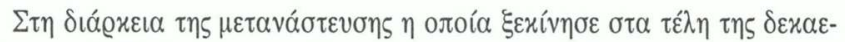

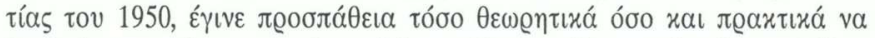

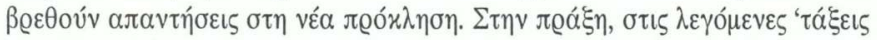

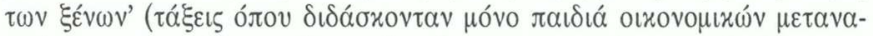

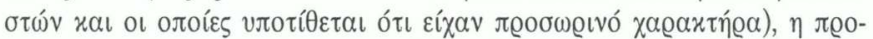

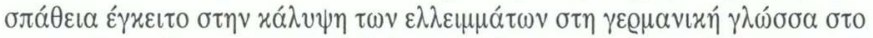

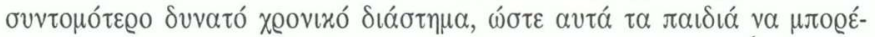

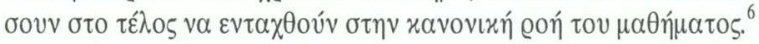

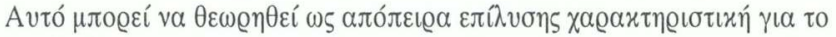

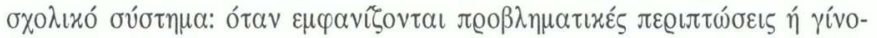

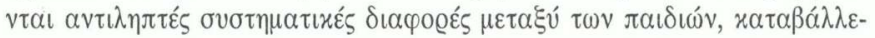

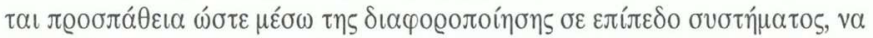

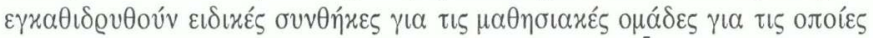

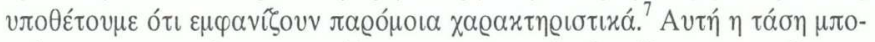

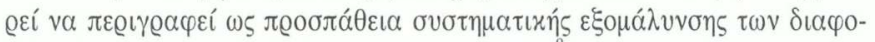

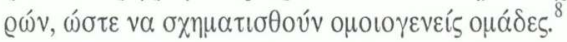

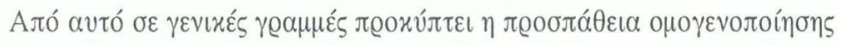

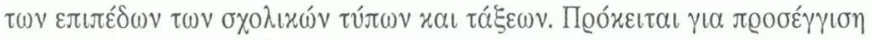

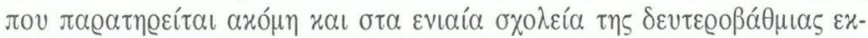

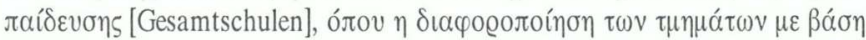

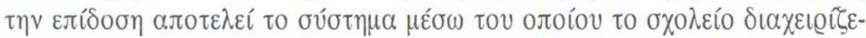

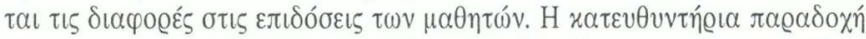

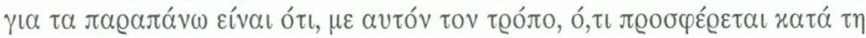

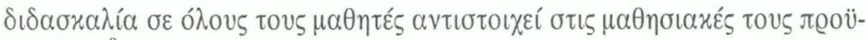

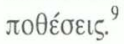

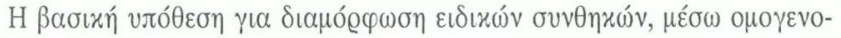

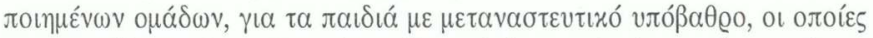

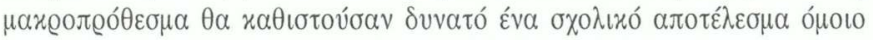

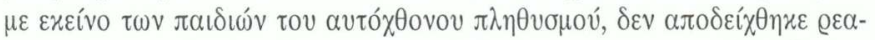

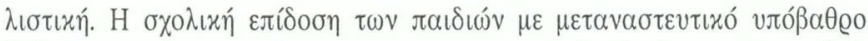

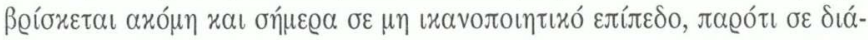

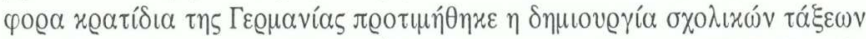

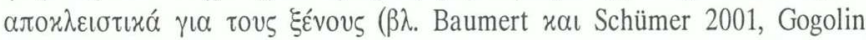
2000, Ramm, Prenzel, Heidemeier xaı Walter 2004). Гı $\alpha \eta v \alpha \tau o \tau v \chi i ́ \alpha \alpha v \tau o v ́$

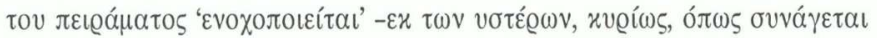




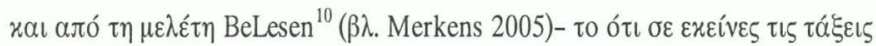

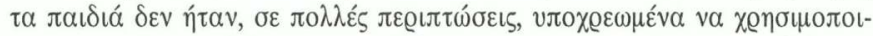

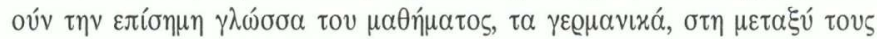

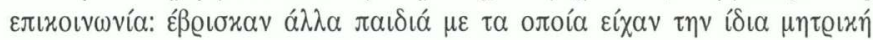

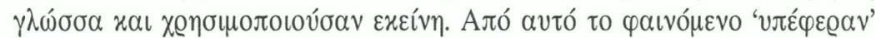

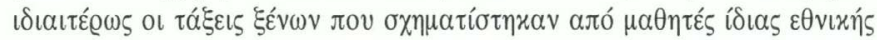

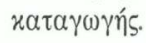

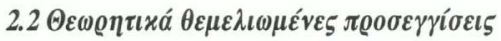

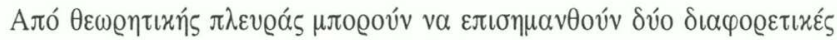

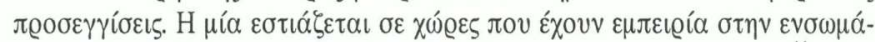

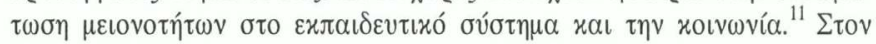

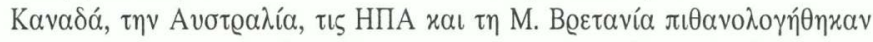

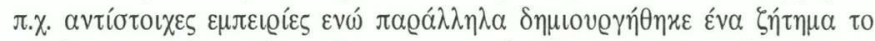

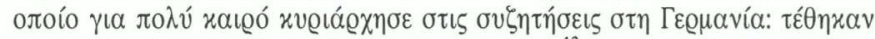

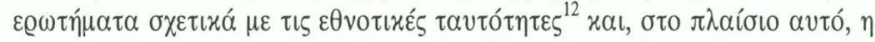

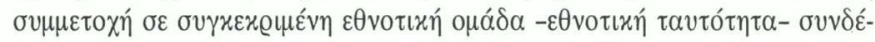

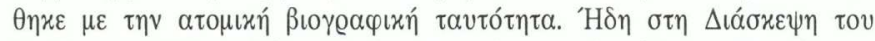

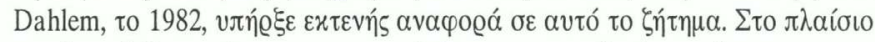

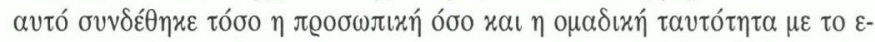

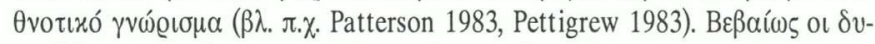

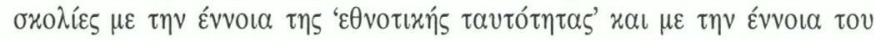

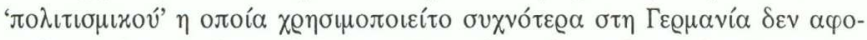

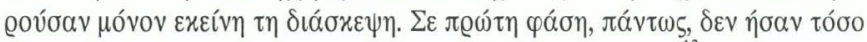

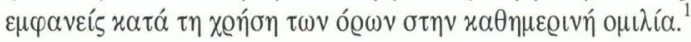

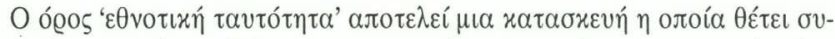

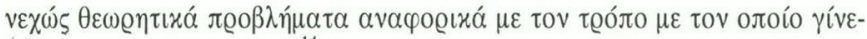

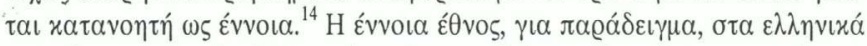

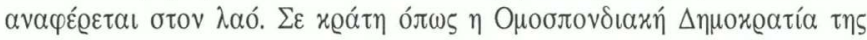

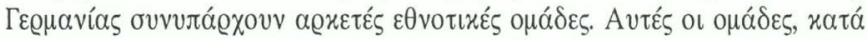

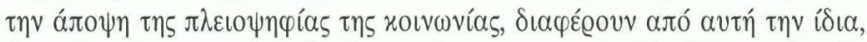

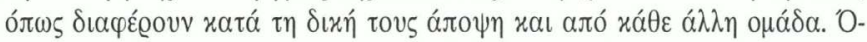

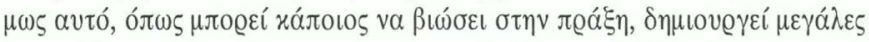

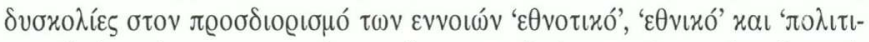

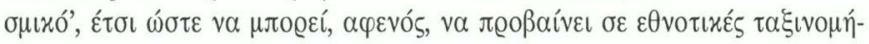




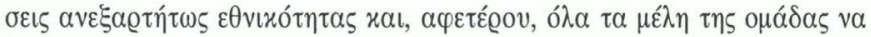

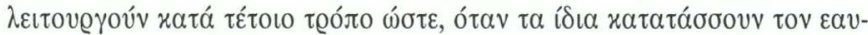

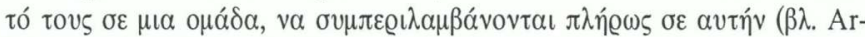

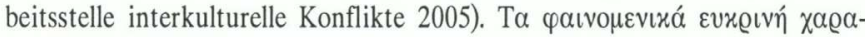

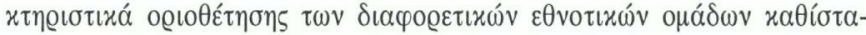

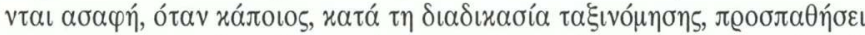

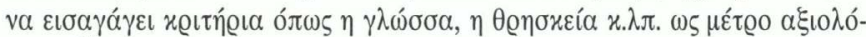

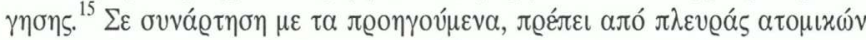

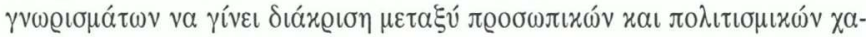

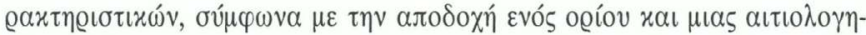

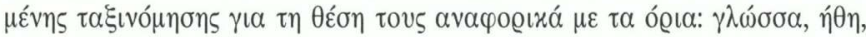

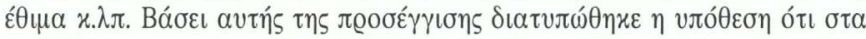

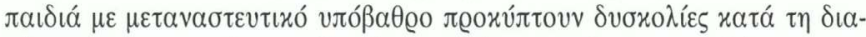

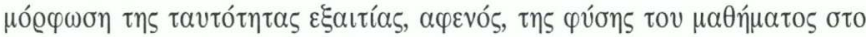

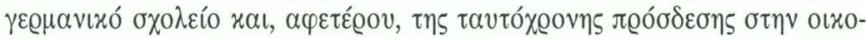

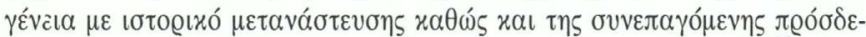

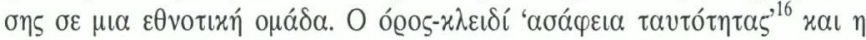

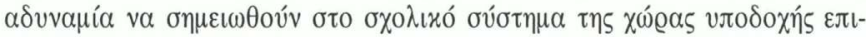

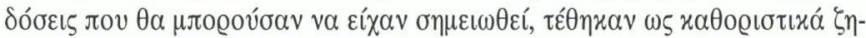

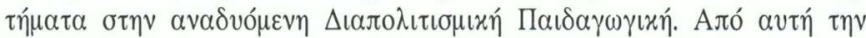

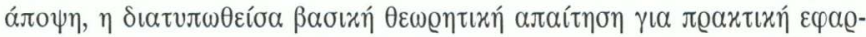

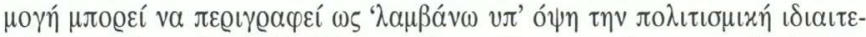

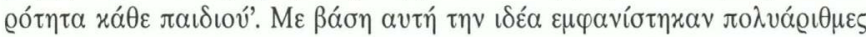

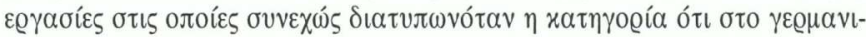

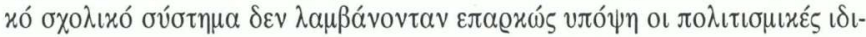

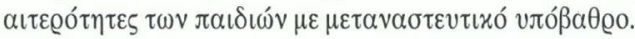

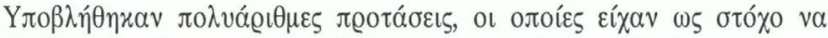

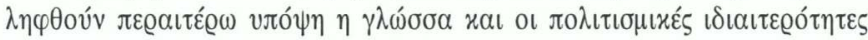

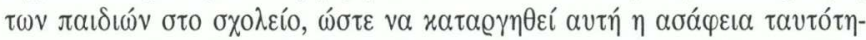

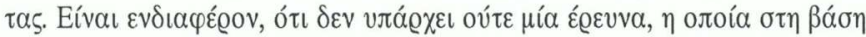

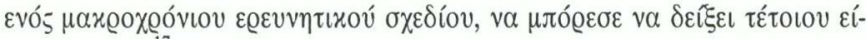

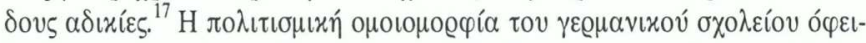

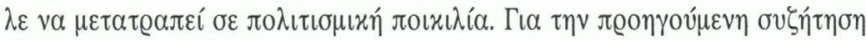

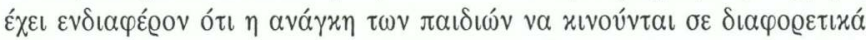

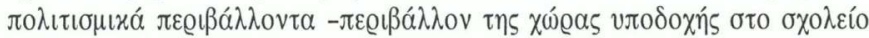




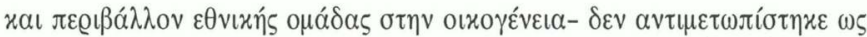

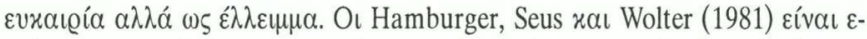

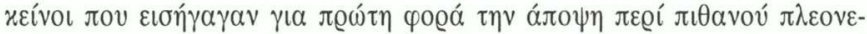

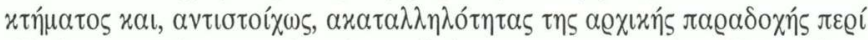

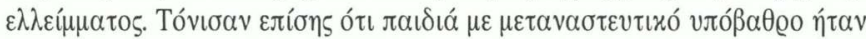

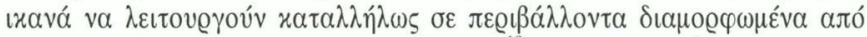

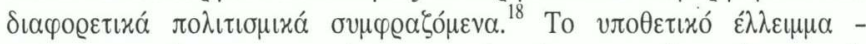

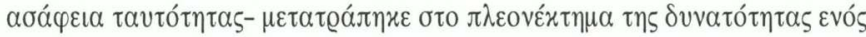

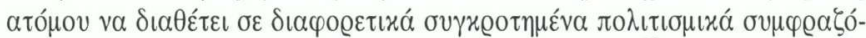

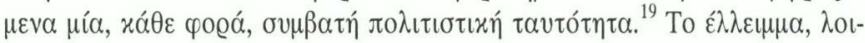

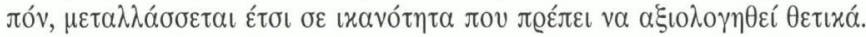

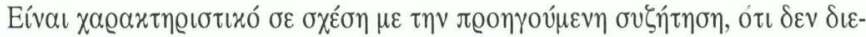

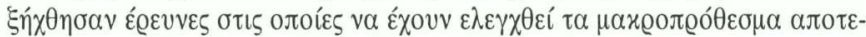

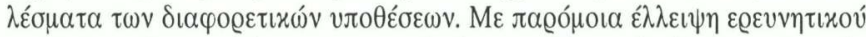

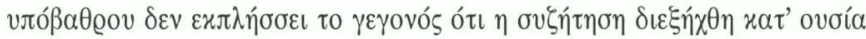

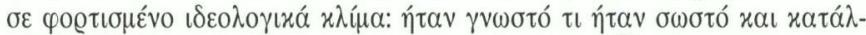

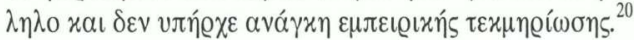

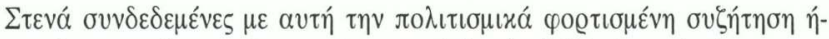

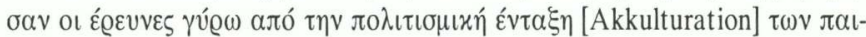

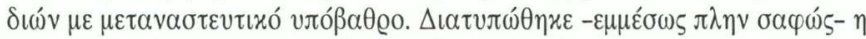

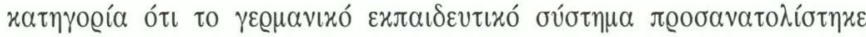

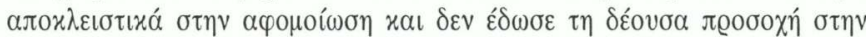

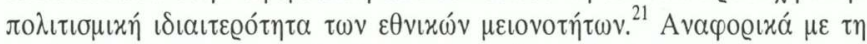

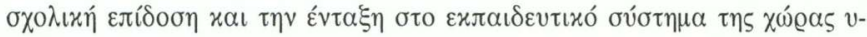

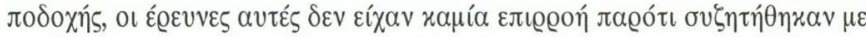

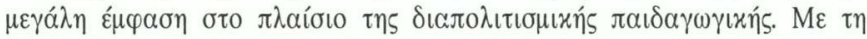

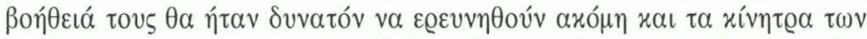

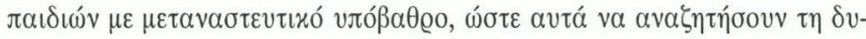

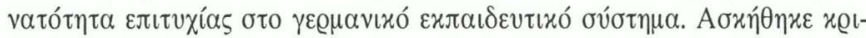

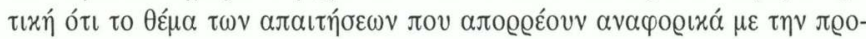

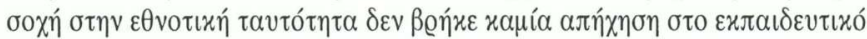

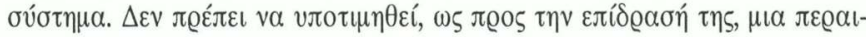

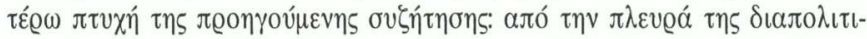

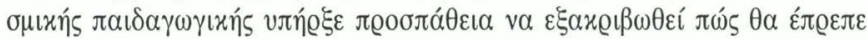

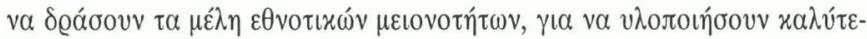




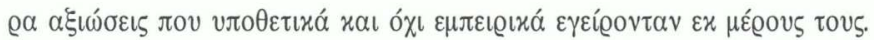

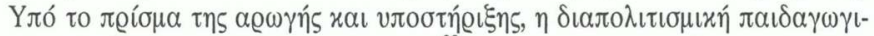

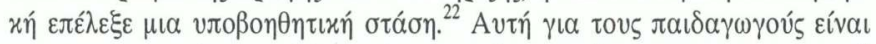
$\mu \iota \alpha$ б

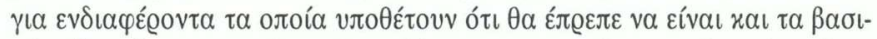

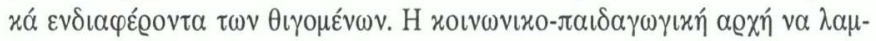

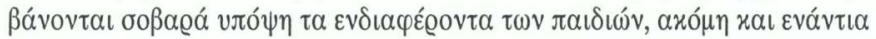

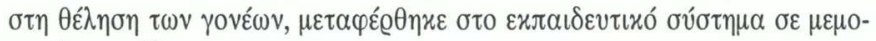

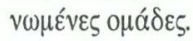

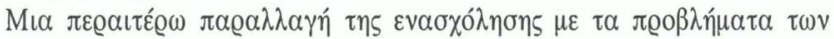

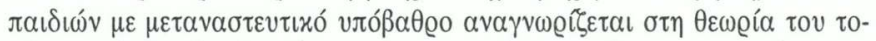

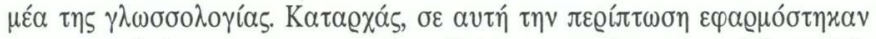

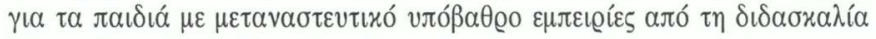

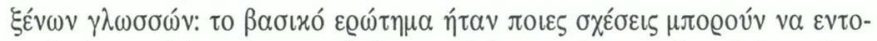

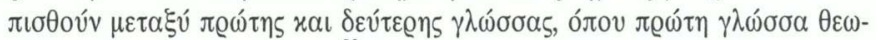

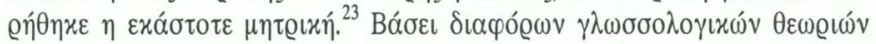

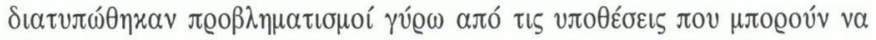

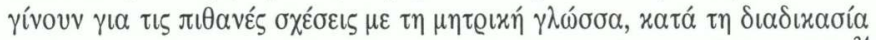

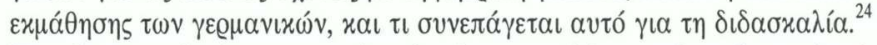

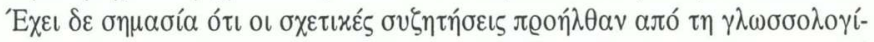

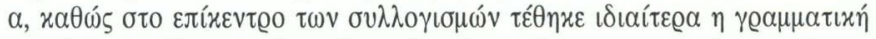

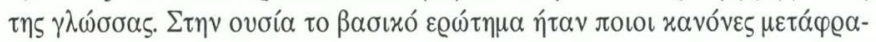

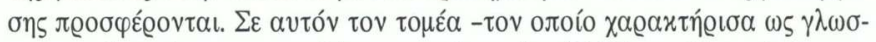

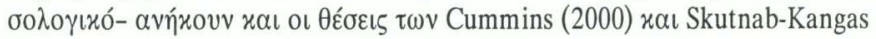

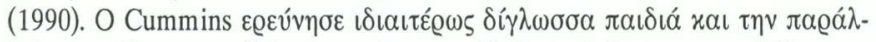

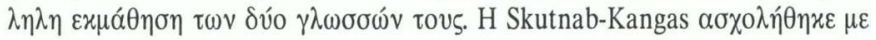

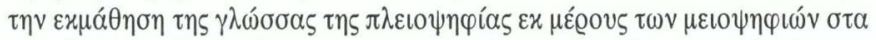

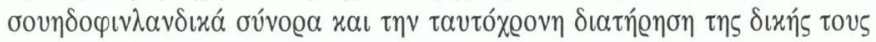

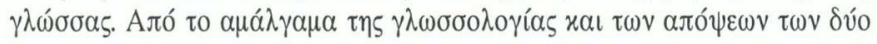

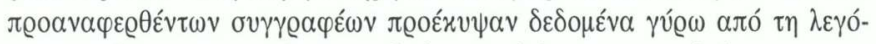

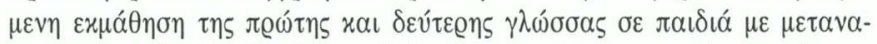

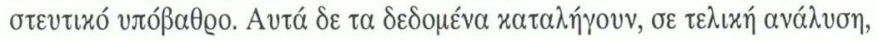

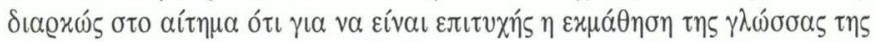

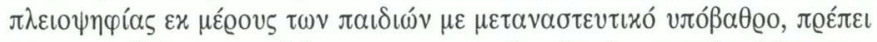

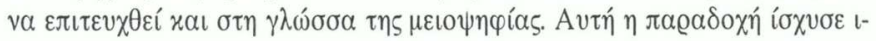




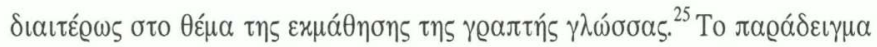

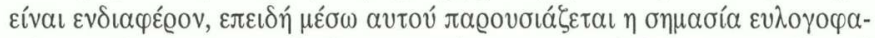

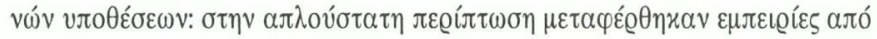

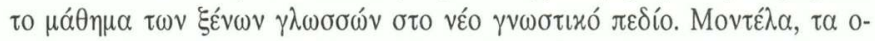

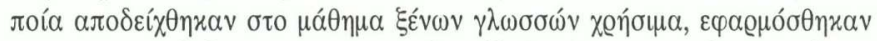

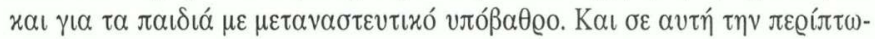

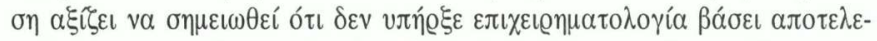

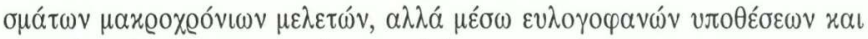

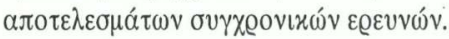

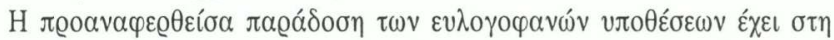

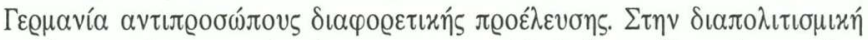

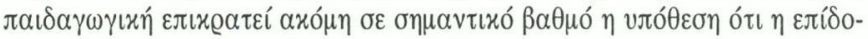

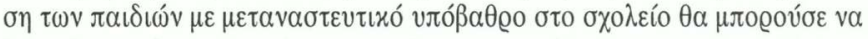

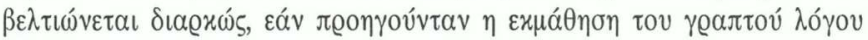

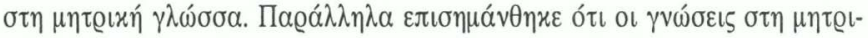

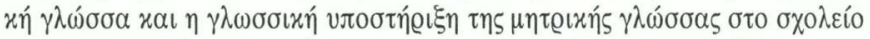

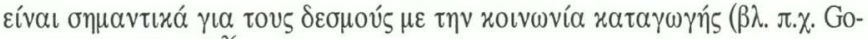

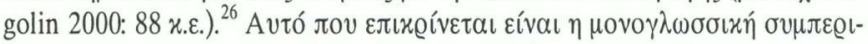

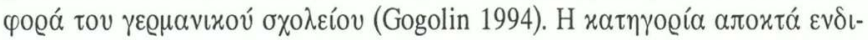

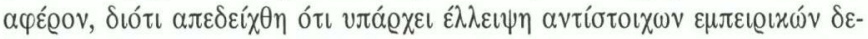

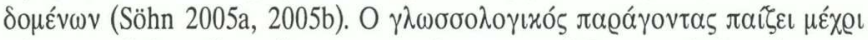

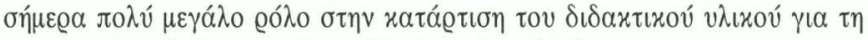

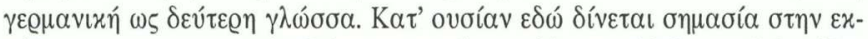

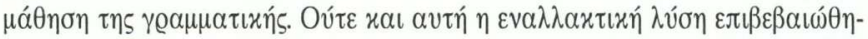

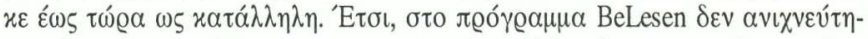

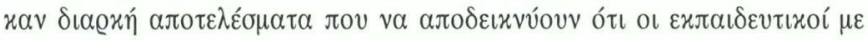

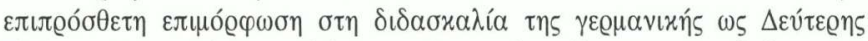

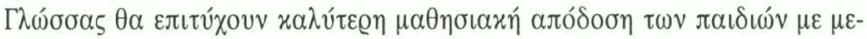

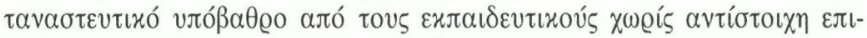

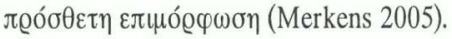

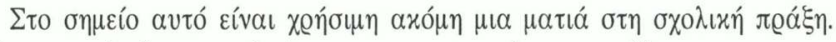

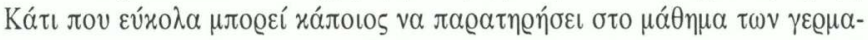

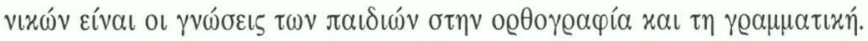

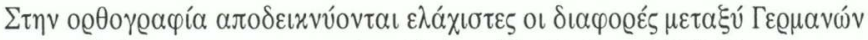

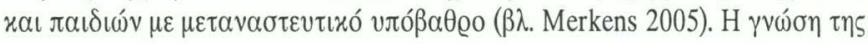




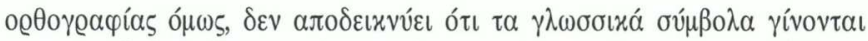

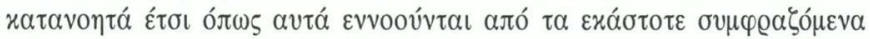

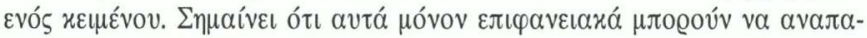

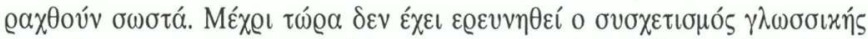

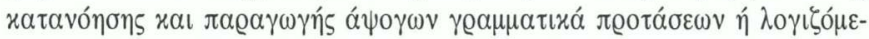

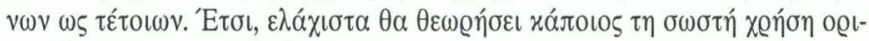

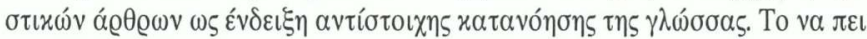

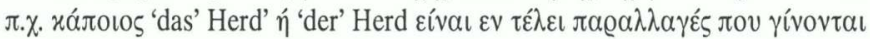

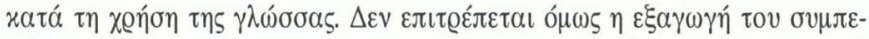

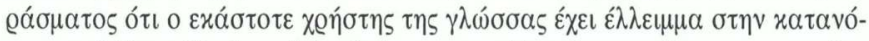

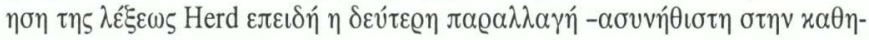

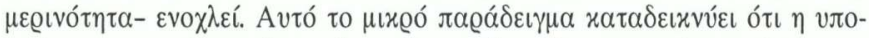

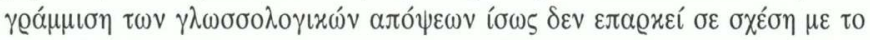

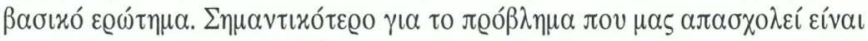

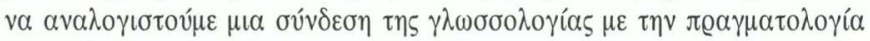

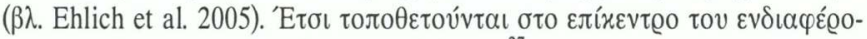

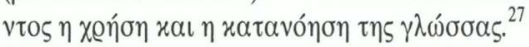

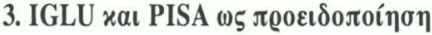

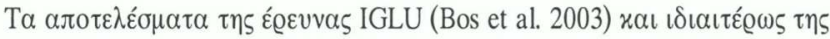

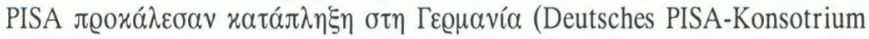

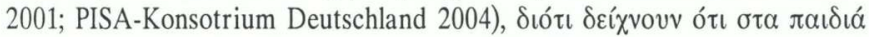

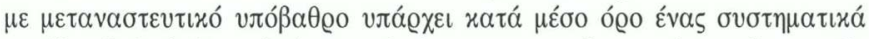

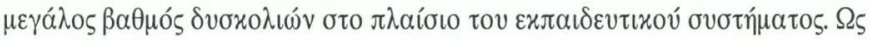

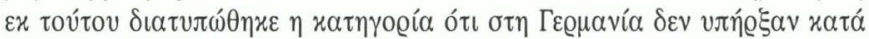

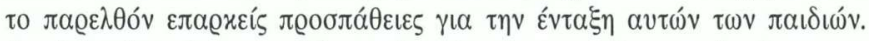

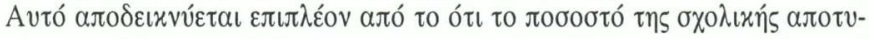

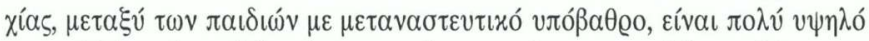

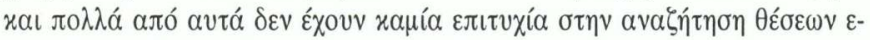

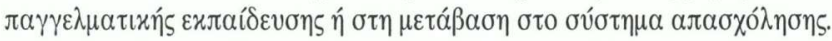

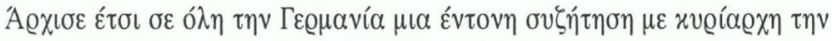

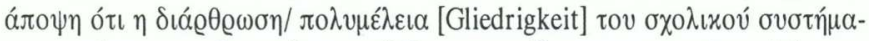

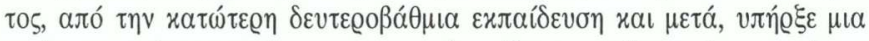

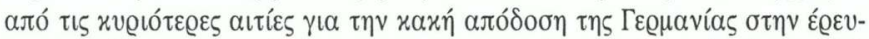

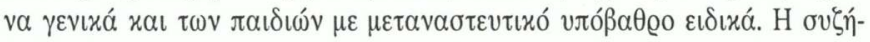




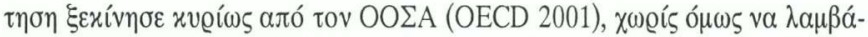

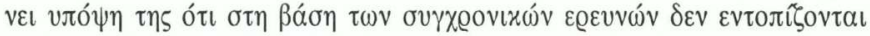

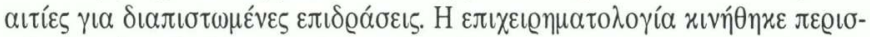

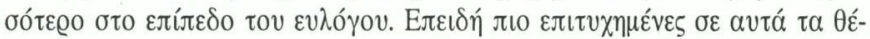

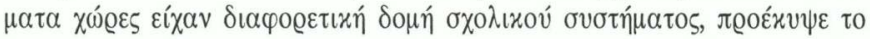

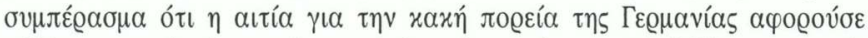

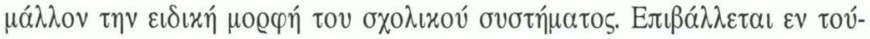

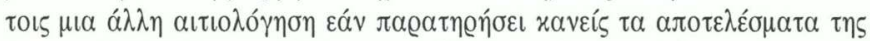

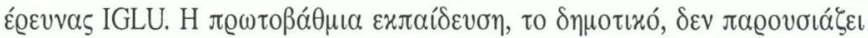

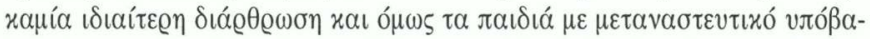

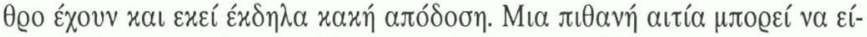

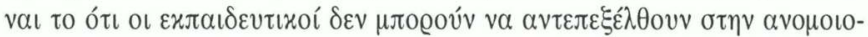

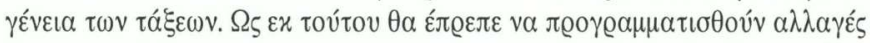

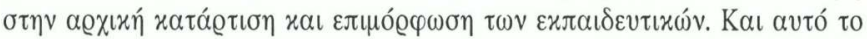

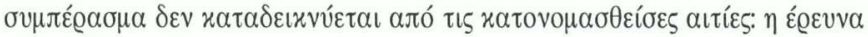

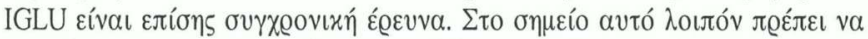

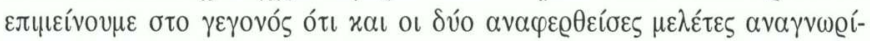

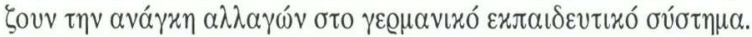

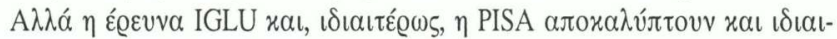

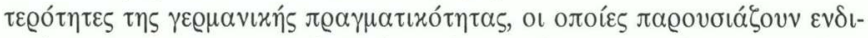

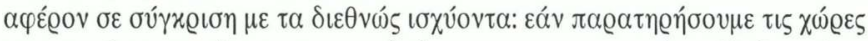

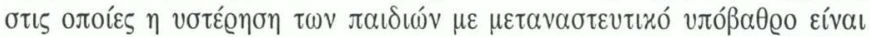

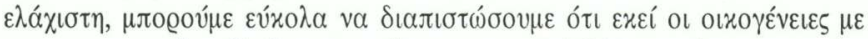

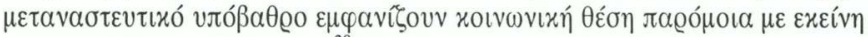

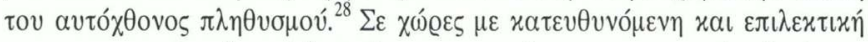

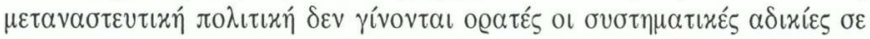

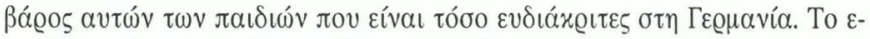

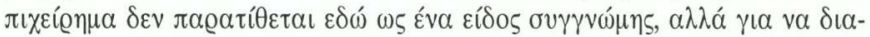

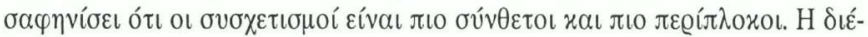

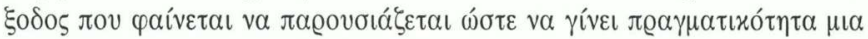

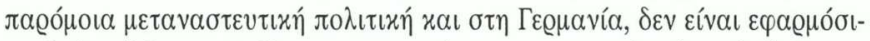

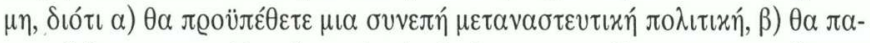

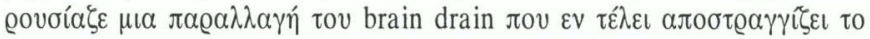

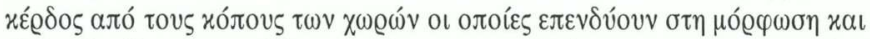

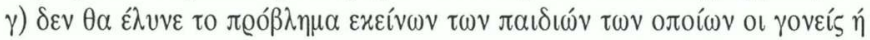




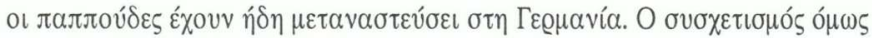

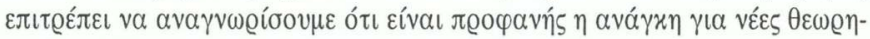

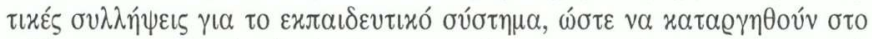

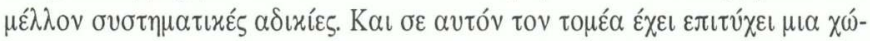

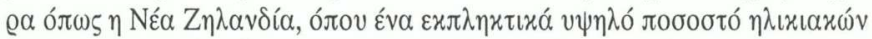

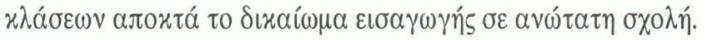

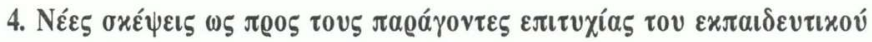

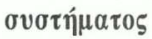

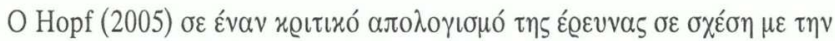

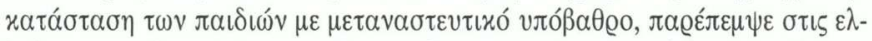

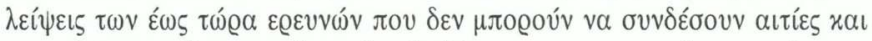

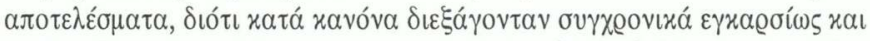

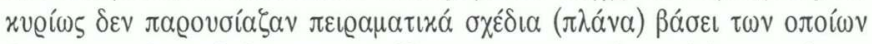

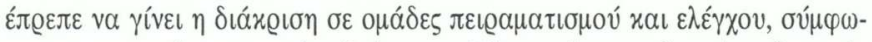

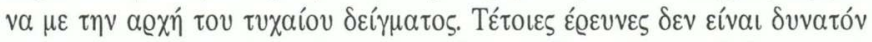

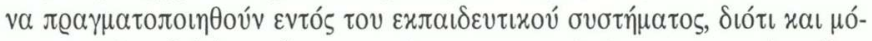

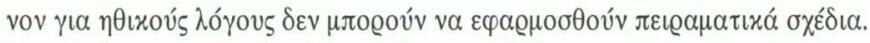

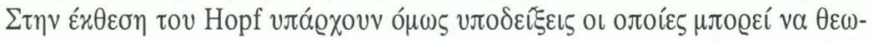

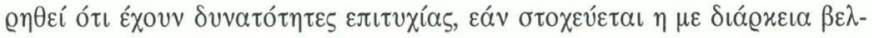

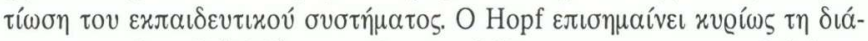

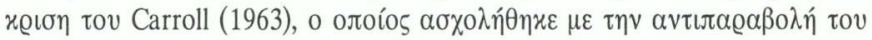

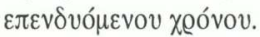

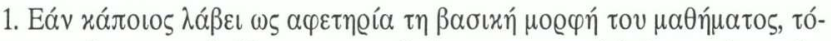

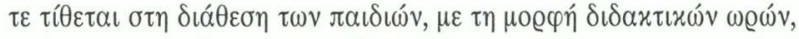

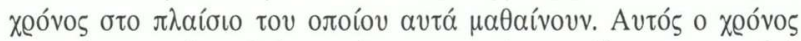

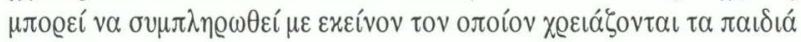

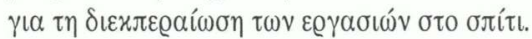

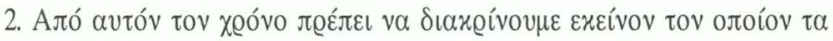

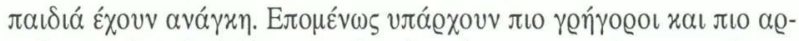

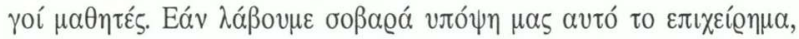

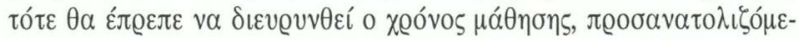

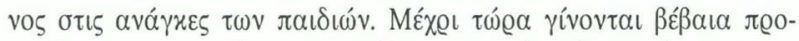

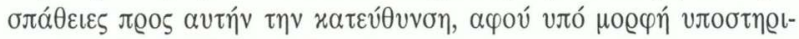

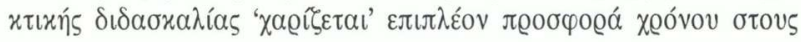




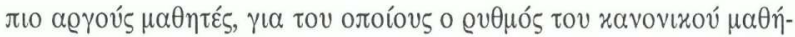

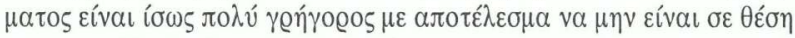

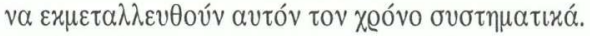

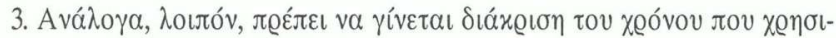

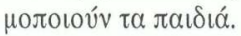

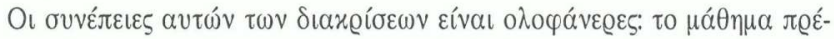

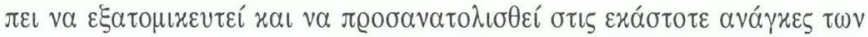

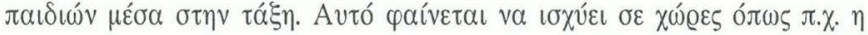

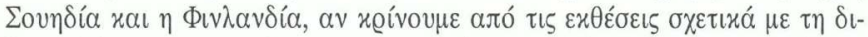

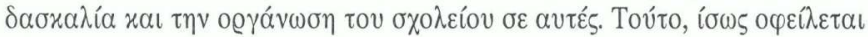

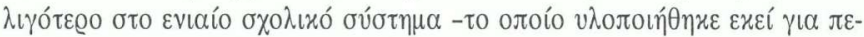

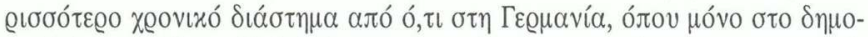

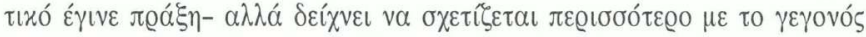

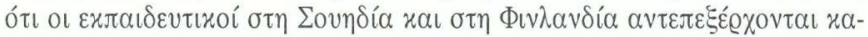

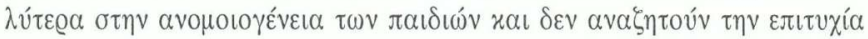

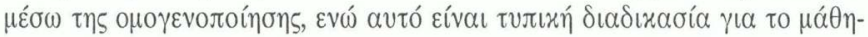

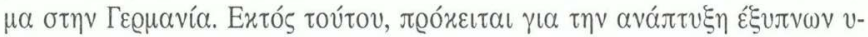

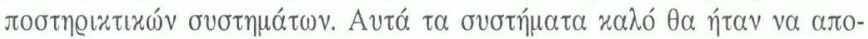

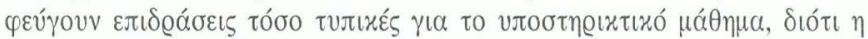

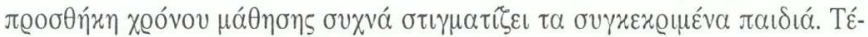

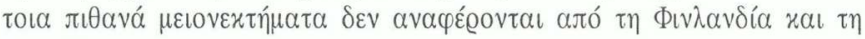

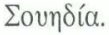

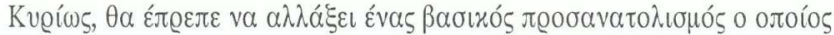

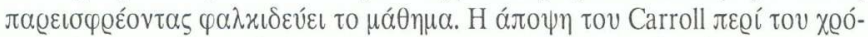

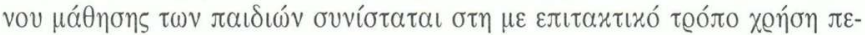

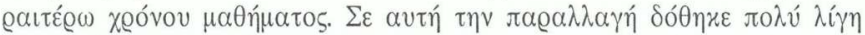

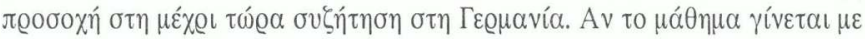

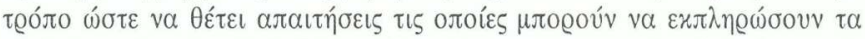

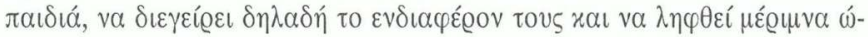

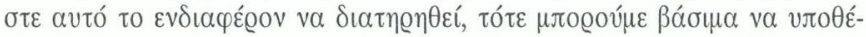

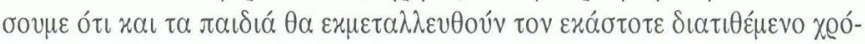

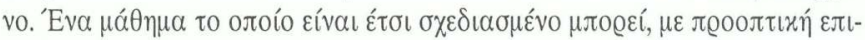

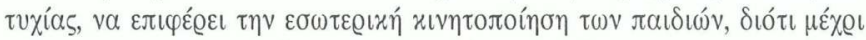

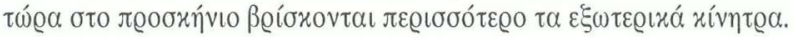




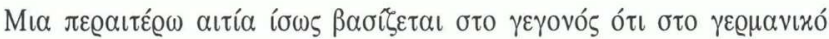

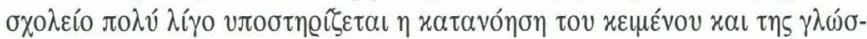

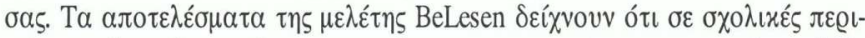

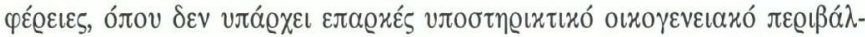

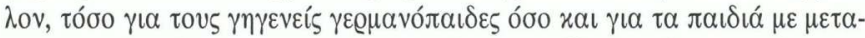

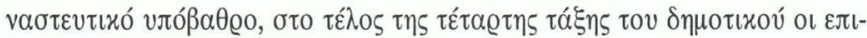

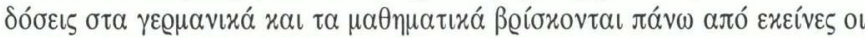

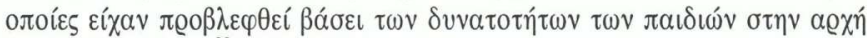

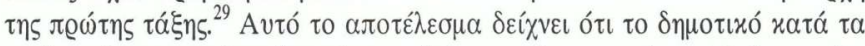

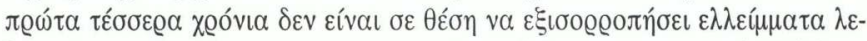

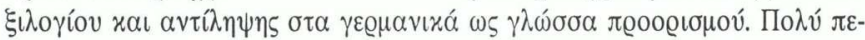

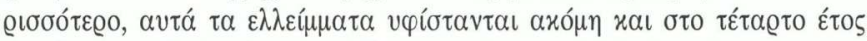

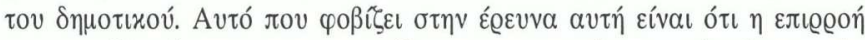

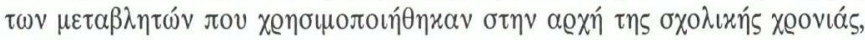

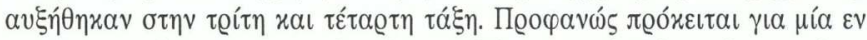

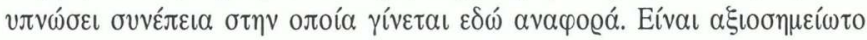

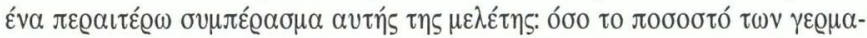

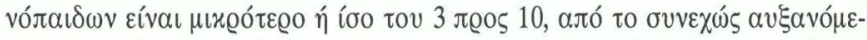

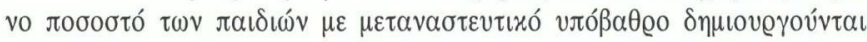

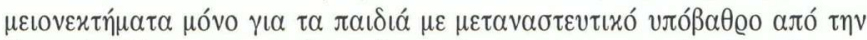

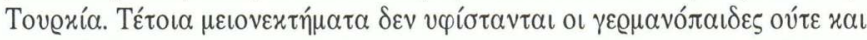

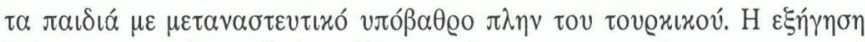

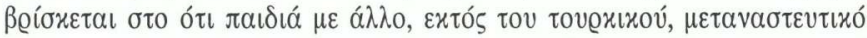

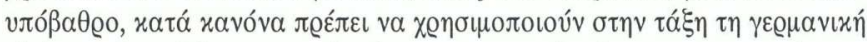

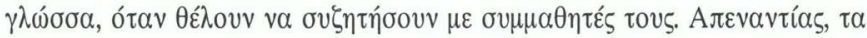

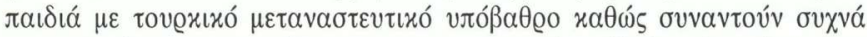

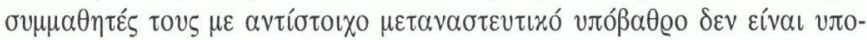

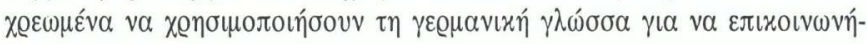

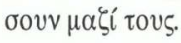

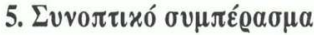

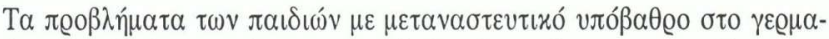

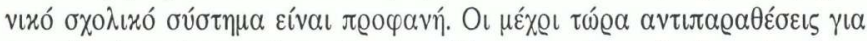

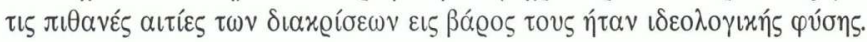




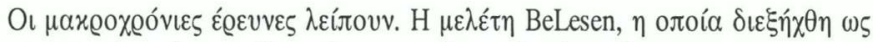

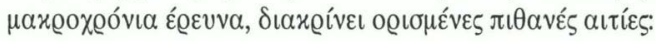

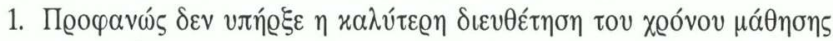

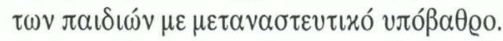

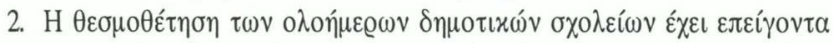

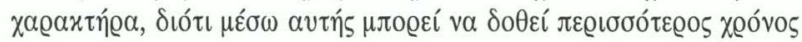

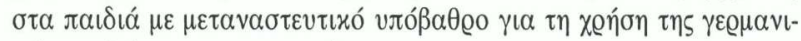

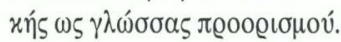

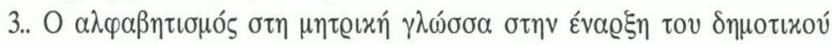

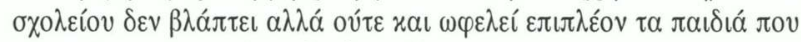

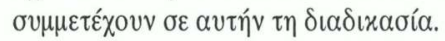

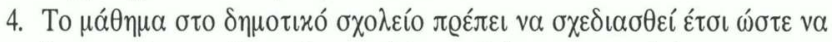

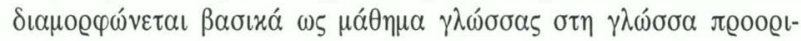

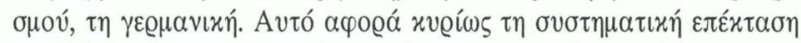

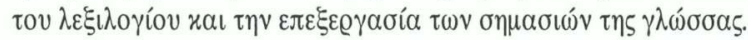

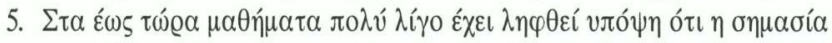

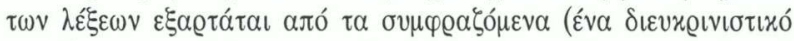

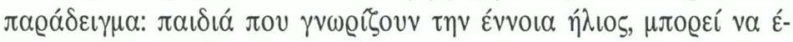

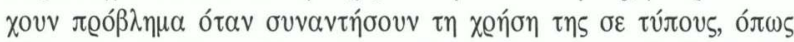

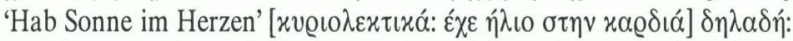

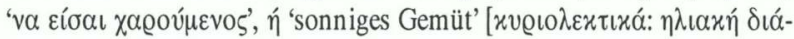

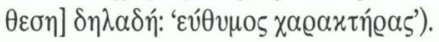

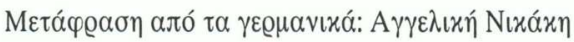

\section{$\Sigma \eta \mu \varepsilon เ \omega ́ \varepsilon เ \varsigma$} 30.

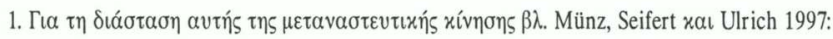

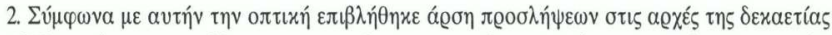

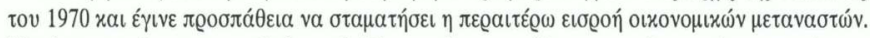

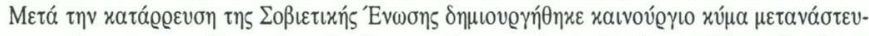

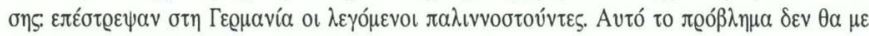

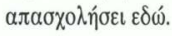

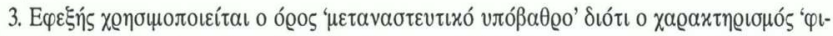

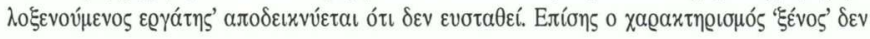




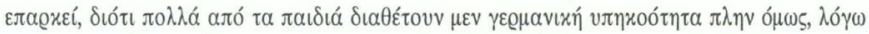

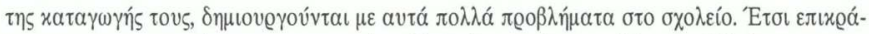

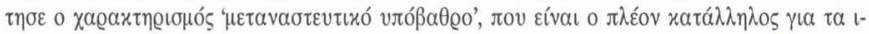

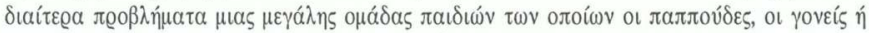

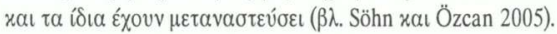

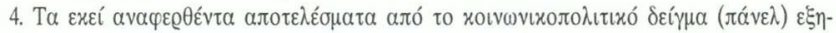

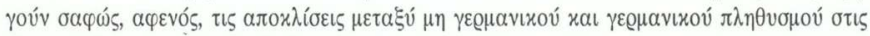

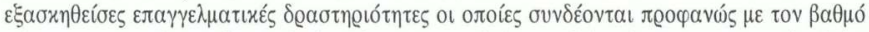

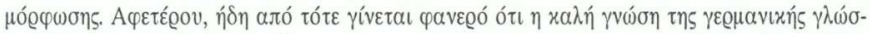

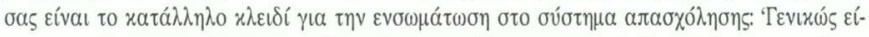

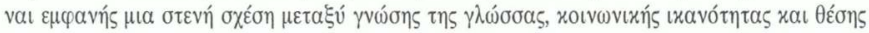

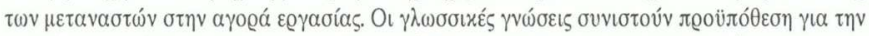

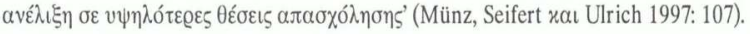

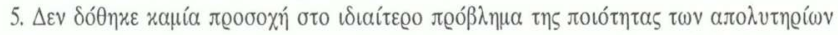

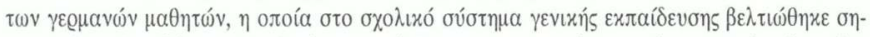

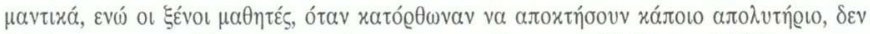

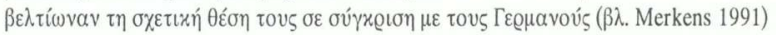

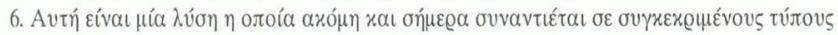

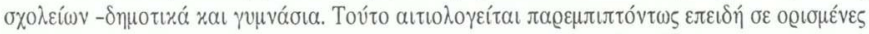

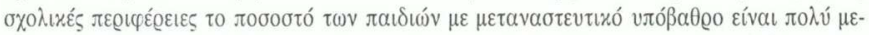

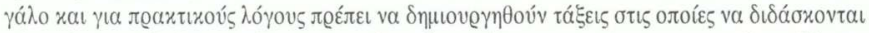

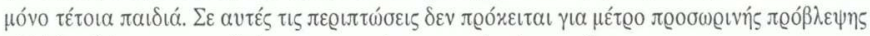

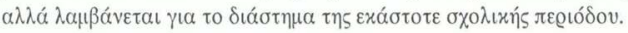

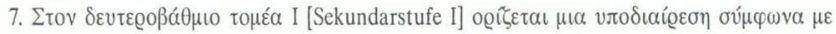

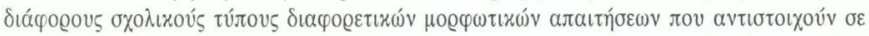

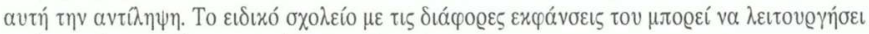

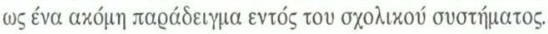

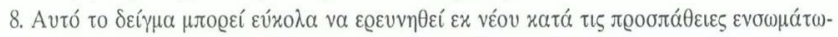

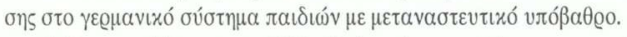

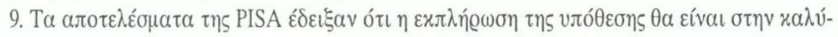

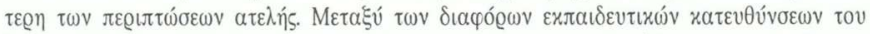

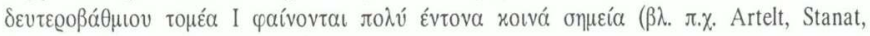
Schneider xaı Schiefele 2001: 121).

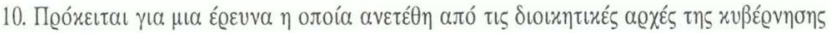

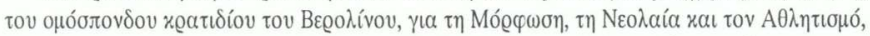

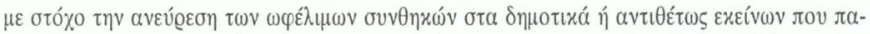

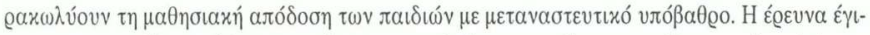

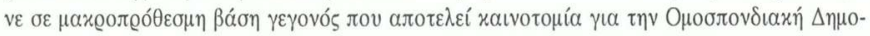

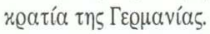




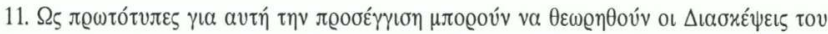

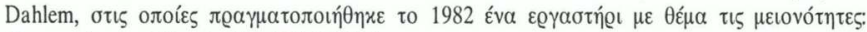
Community and Identity ( $\beta \lambda$. Fried 1983).

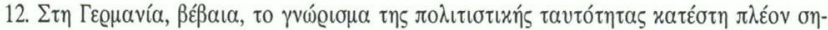

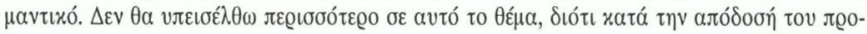

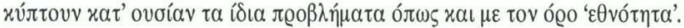

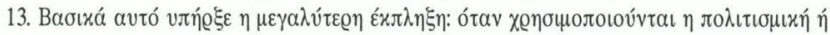

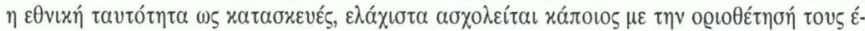

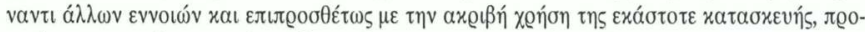

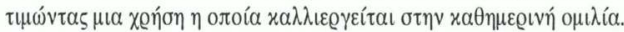

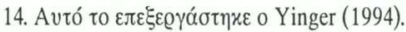

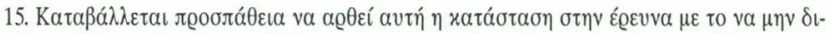

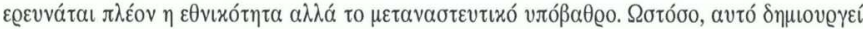

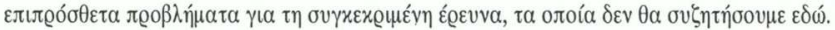

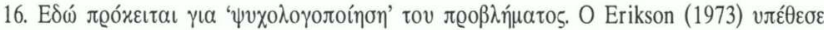

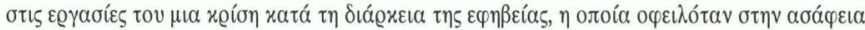

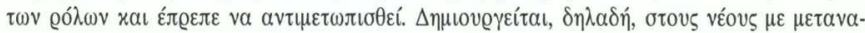

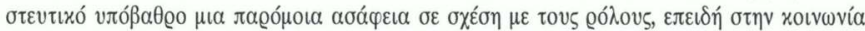

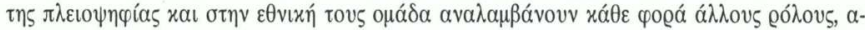

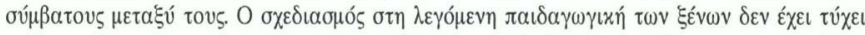

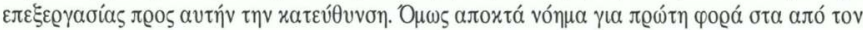

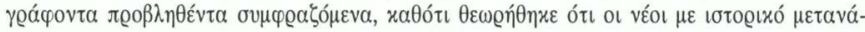

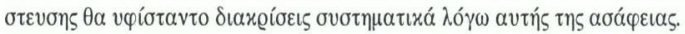

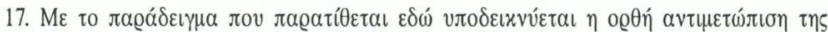

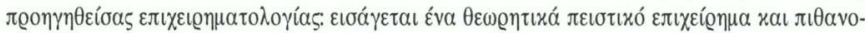

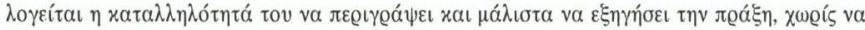

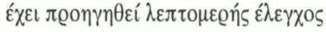

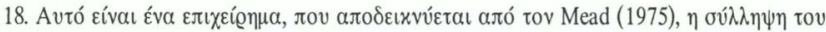

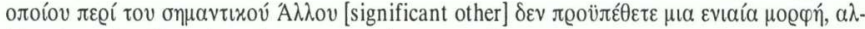

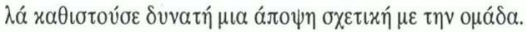

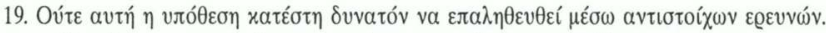

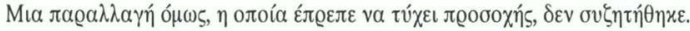

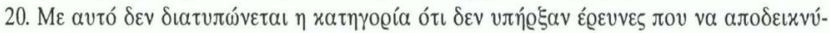

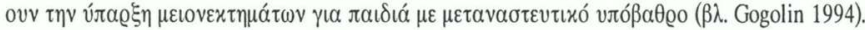

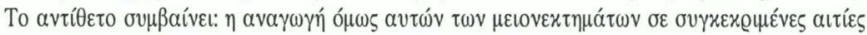

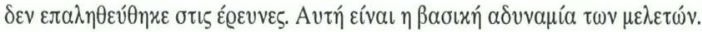

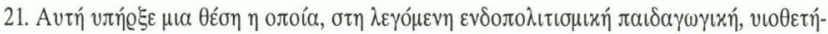

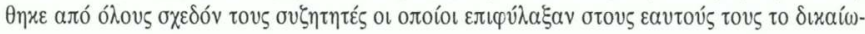




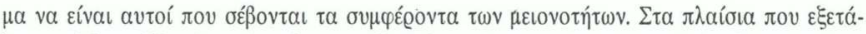

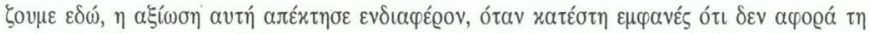

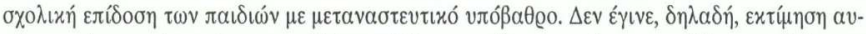

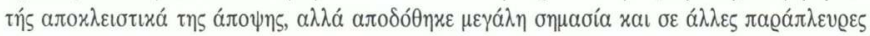

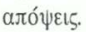

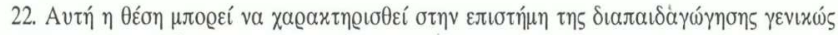

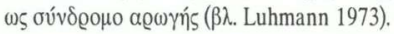

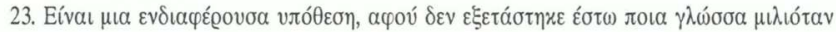

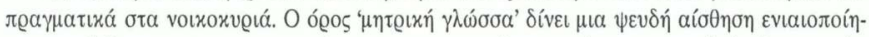

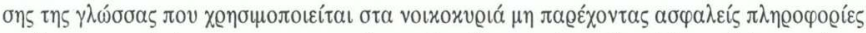

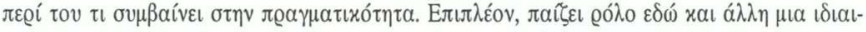

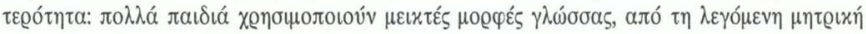

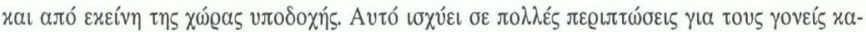

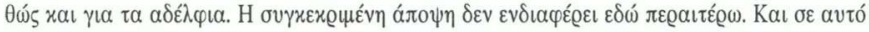

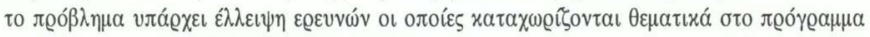
PISA ( $\beta \lambda$. Deutsches PISA-Konsortium 2001, PISA Konsortium Deutschland 2004).

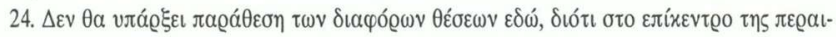

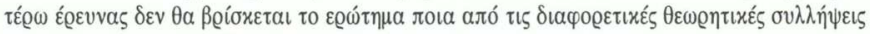

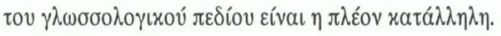

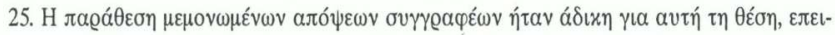

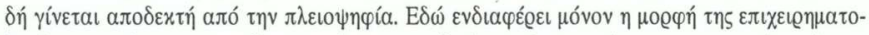

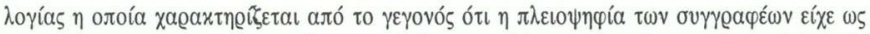

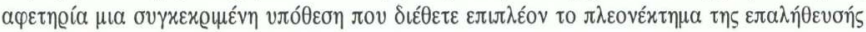

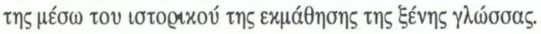

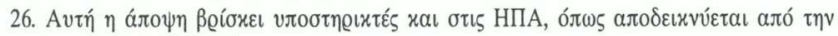

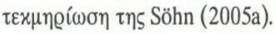

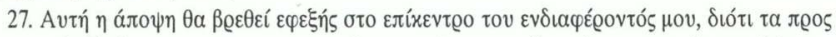

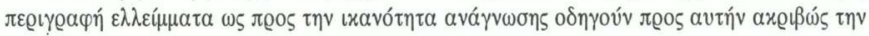

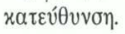

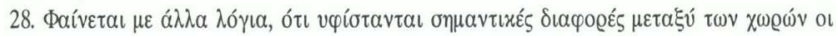

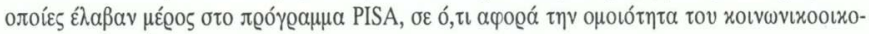

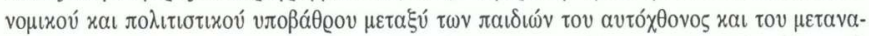

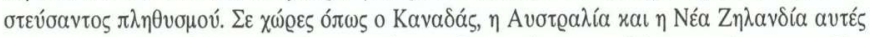

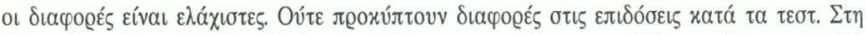

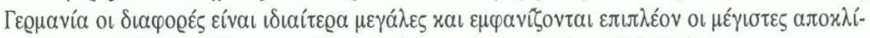

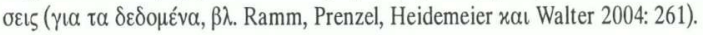

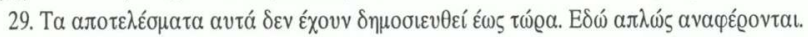




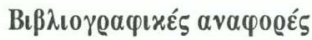

Arbeitsstelle interkulturelle Konflikte (єлчц.) (2005). Migrationshintergrund von Kindern und Jugendlichen: Wege zur Weiterentwicklung der amtlichen Statistik. Bildungsreform Bd. 14. Berlin: Bundesministerium für Bildung und Forschung.

Artelt, C., Stanat, P., Sschneider, W., Schiefele U. (2001). 'Lesekompetenz: Testkon-

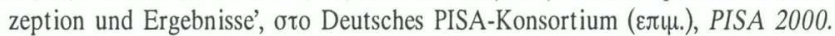
Basiskompetenzen von Schülerinnen und Schülern im internationalen Vergleich. Opladen: Leske +Budrich.

Baumert, J., Schümer, G. (2001). 'Familiäre Lebensverhältnisse, Bildungsbeteiligung und Kompetenzerwerb', oro Deutsches PISA-Konsortium (єлч.), PISA 2000. Basiskompetenzen von Schülerinnen und Schülern im internationalen Vergleich. Opladen : Leske+Budrich.

Bos, W. et. al. (2003). Erste Ergebnisse aus IGLU. Schülerleistungen am Ende der vierten Jahrgangsstufe im internationalen Vergleich. Münster: Waxmann.

Carroll, J. B. (1963). 'A Model of School Learning', Teacher's College Record, 64: 723-733.

Cummins, J. (2000). Language and Pedagogy. Bilingual Children in the Crossfire, Clevedon: Multilingual Matters.

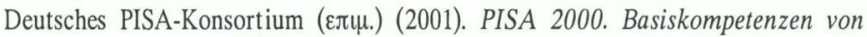
Schülerinnen und Schülern im internationalen Vergleich. Opladen: Leske +Buderich.

Ehlich, K. (2005). 'Sprachaneignung und deren Feststellung bei Kindern mit und ohne Migrationshintergrund: Was man weiß, was man braucht, was man erwarten kann', oto Bundesministerium für Bildung und Forschung (Hrsg.): Anforderungen an Verfahren der regelmäßigen Sprachstandsfeststellung als Grundlage für die frühe und individuelle Förderung von Kindern mit und ohne Migrationshintergrund, Bildungsreform Bd. II, Bonn : BMBF, 11-76.

Erikson, E.H. (1973). Identität und Lebenszyklus. Stw, Bd. 16, Frankfurt: Suhrkamp.

Fried, C. (1983). Minorities: Community and Identity. Berlin Springer.

Gogolin, I. (1994). Der monolinguale Habitus der multilingualen Schule. Münster: Waxmann. 
Gogolin, I. (2000). 'Bildung und ausländische Familien', oтo: Sachverständiger-

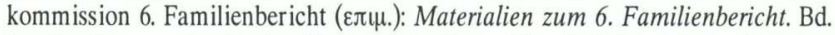
II: Familien ausländischer Herkunft in Deutschland: Lebensalltag., Opladen: Leske+Budrich, 61-106.

Hamburger, Franz, Seus, Wolter, Otto (1981). 'Über die Unmöglichkeit Politik durch Pädagogik zu ersetzen', Unterrichtswissenschaft, 158-167.

Herwartz-Emden, L. (2003). 'Einwandererkinder im Deutschen Bildungswesen', $\sigma \tau 0$ Cortina, K. S., Baumert, J., Leschinsky, A., Mayer, K-U., Trommer, L. (єлા.), Das Bildungswesen in der Bundesrepublik Deutschland. Strukturen und Entwicklungen im Überblick. Rororo Bd. 61122, Reinbeck: Rowohlt, 661-710.

Hopf, D. (1978). Herkunft und Schulbesuch ausländischer Kinder. Eine Untersuchung am Beispiel griechischer Schüler. Max-Plank-Institut für Bildungsforschung. Studien und Berichte 44. Berlin MPI.

Hopf, D. (2005). 'Zweisprachigkeit und Schulleistung bei Migrantenkindern', Zeitschrift für Pädagogik, 51.Jg., 236-251.

Krüger-Portratz, M. (1992). Interkulturelle Erziehung und Zweisprachigkeit. Baltmannsweiler: Schneider Verlag Hohengehren.

Luhmann, N. (1973). 'Formen des Helfens im gesellschaftlichen Wandel', oro Otto, H-U., Utermann, K. (єлщц.), Sozialarbeit als Beruf, Neuwied: Luchterhand, 21ff.

Mead, G. H. (1975). Geist, Identität und Gesellschaft. Stw Bd. 28. Frankfurt: Suhrkamp.

Merkens, H. (1991). 'Chancen von Schülern aus Minderheiten im deutschen Schulsystem und die Forderung nach allgemeiner Bildung unter besonderer Berück-

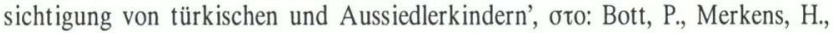

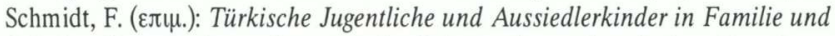
Schule. Theoretische und empirische Beiträge der pädagogischen Forschung. Baltmannsweiler: Schneider Verlag Hohengehren.

Merkens, H. (2005). Schulkarrieren von Kindern mit Migrationshintergrund in den ersten drei Jahren der Grundschule. Berichte aus der Arbeit des Arbeitbereichs Empirische Erziehungswissenschaft der FU Berlin. Nr. 43, Berlin: FU Berlin, Arbeitsbereich Empirische Erziehungswissenschaft.

Münz, R., Seifert, W., Ulrich, R. (1997). Zuwanderung nach Deutschland. Strukturen, Wirkungen, Perspektiven. Frankfurt/M: Campus.

OECD (2001). Lernen für das Leben. Erste Ergebnisse von PISA 2000. Ausbildung und Kompetenzen. Paris: OECD. 
Patterson, O. (1983). 'The Nature, Causes, and Implications of Ethnic Identifica-

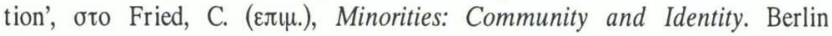
Springer.

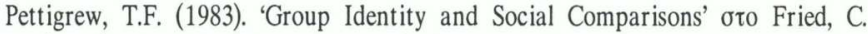

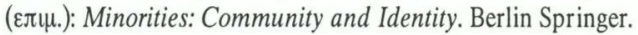

PISA-Konsortium Deutschland (Hrsg.) (2004): Der Bildungsstand der Jugendlichen in Deutschland. Ergebnisse des zweiten internationalen Vergleichs. Münster.

Ramm, C., Prenzel, M., Heidemeier, H., Walter, O. (2004). 'Soziokulturelle Herkunft: Migration', oтo PISA-Konsortium Deutschland (Hrsg.), Der Bildungsstand der Jugendlichen in Deutschland-Ergebnisse des zweiten internationalen Vergleichs. Münster: Waxmann.

Siewert, P. (1980). 'Zur Entwicklung der Gastarbeiterpolitik und der schulpolitischen Abstimmung der Kultusministerkonferenz'. I: Projektgruppe Bildungsbe-

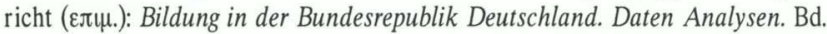
2, rororo, Bd. 7338, Reinbeck: Rowohlt, 1053-1112.

Skutnab-Kangas, T. (1990). Language, Literacy and Minorities. London: The Minority Rights Group.

Söhn, J. (2005a). Zweisprachiger Schulunterricht für Migrationskinder. Ergebnisse der Evaluatiosforschung für seine Auswirkungen auf Zweispracherwerb und Schulerfolg. AKI Forschungsbilanz Nr. 2. Wissenschaftszentrum Berlin: Arbeitsstelle interkulturelle Konflikte und gesellschaftliche Integration. Berlin: WZB.

Söhn, J. (єлчu.) (2005b). The Effectiveness of Bilingual School Programs for Immigrant Children. Wissenschaftszentrum Berlin. Discussion Papers. Berlin: WZB.

Söhn, J., Özcan, V. (2005). 'Bildungsdaten und Migrationshintergrund', oтo Bun-

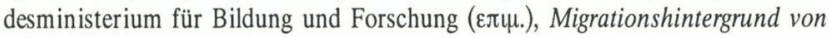
Kindern und Jugendlichen. Bildungsreform, Bd. 14. Bonn : BMBF.

Yinger, J. M. (1994). Ethnicity Source of Strength? Source of Conflict?, New York: State University of New York Press. 